\title{
Crescimento e fitoextração em espécies em espécies florestais após adição de lodo de curtume no substrato
}

\author{
Growth and phytoextraction in forest species after \\ addition of tannery sludge in substrate
}

\author{
Daniele Mozzini Silva1, Ademir Sergio Ferreira de Araujo² e Fabio Fernando de Araujo ${ }^{3}$
}

\begin{abstract}
Resumo
Este trabalho teve como objetivo avaliar o crescimento das mudas de espécies florestais após a adição do lodo de curtume como componente de substrato comercial, na produção de quatro espécies nativas: angico vermelho (Anadenanthera colubrina), angico branco (Anadenanthera macrocarpa), aroeira salsa (Schinus mole), mutambo (Guanzuma ulmifolia) e uma exótica: eucalipto (Eucalyptus urophylla) como também avaliar a fitoextração de nutrientes e de cromo do substrato. Foram avaliadas cinco doses: 5,10 , 15,20 e $25 \%$ de lodo curtume na composição do substrato comercial a base de casca de pinus. Após a semeadura no substrato acondicionado em tubetes, de acordo com cada tratamento, foi acompanhado o desenvolvimento das mudas, durante 120 dias, com avaliações de diâmetro de colo e de produção de biomassa no sistema radicular e parte aérea das nas plantas, como também foram avaliados os teores de macro e micronutrientes, acúmulo de cromo no tecido foliar e teor final de cromo no substrato. As espécies de aroeira salsa, eucalipto e mutambo responderam positivamente à adição de até $25 \%$ de lodo de curtume no substrato. Sendo que a aroeira salsa apresentou a maior capacidade de absorção de cromo na parte aérea e também se destacou como a espécie de melhor crescimento em resposta a adição do lodo no substrato. O teor de cromo no substrato foi reduzido após o crescimento das mudas, sendo menor quando se produziu o eucalipto.
\end{abstract}

Palavras-chave: Resíduos orgânicos; reciclagem; cromo.

\begin{abstract}
This study aims to evaluate the use of tannery sludge as a component of commercial substrate, to produce seedlings for reforestation of four native species: Anadenanthera colubrina; Anadenanthera macrocarpa; Schinus mole; Guanzuma ulmifolia) and one exotic species: Eucalyptus urophylla; and also to evaluate the removal of nutrients and chromium from the substrate. This study evaluated the incorporation of five doses $(5,10,15,20$ and $25 \%)$ of tannery sludge used in commercial substrate for growth of different native and exotic species suitable for reforestation. The experiment was conducted in greenhouse seedling growth. After sowing into substrate in tubes, each treatment was examined for plant development for 120 days, with periodic assessment of height and final evaluation of biomass (roots and shoots) in plants; contents of macro and micronutrients and accumulation of chromium in the leaf tissue was also examined. Three forest species responded positively to the addition of up to $25 \%$ of tannery sludge on the substrate to produce seedlings. Schinus mole showed a high absorption of chromium into the shoot and also provided the best growth in response to sludge addition on the substrate. Chromium content in the substrate was reduced after cultivation of forest species, with emphasis on the performance found by eucalyptus seedlings.
\end{abstract}

Keywords: Organic waste; recycling; chromium.

\section{INTRODUÇÃO}

O lodo é um resíduo sólido produzido após o tratamento de águas residuárias que podem ter origem agroindustrial ou urbana. O aumento da urbanização e industrialização tem resultado em aumento no volume de lodos produzidos em todo o mundo, por exemplo, a atividade industrial americana gera e dispõe aproximadamente 7,6 bilhões de toneladas de resíduos sólidos industriais por ano (SANTOS 2010). Enquanto no Brasil, são gerados cerca de 97 milhões de toneladas (IPEA 2012).

${ }^{1}$ Engenheiro ambiental. UNOESTE - Universidade do Oeste Paulista. Rua José Bongiovani, 700 - Cidade Universitária 19050-920 - Presidente Prudente, SP, Brasil. E-mail: dani mozzini@hotmail.com.

${ }^{2}$ Professor Associado. UFPI - Universidade Federal do Piauí / Centro de Ciências Agrárias. Campus da Socopo - 64000-000 - Teresina, PI, Brasil. E-mail: asfaruaj@yahoo.com.br.

3Professor Doutor. UNOESTE - Universidade do Oeste Paulista. Rua José Bongiovani, 700 - Cidade Universitária - 19050920 - Presidente Prudente, SP, Brasil. E-mail: fabio@unoeste.br.

Sci. For., Piracicaba, v. 44, n. 112, p. 1019-1028, dez. 2016

DOI: dx.doi.org/10.18671/scifor.v44n112.23 
Os curtumes são grandes produtores de lodo e sempre foram conhecidos como vilões do meio ambiente; conceito este que remonta do tempo em que não havia nenhum tratamento dos resíduos, sendo estes totalmente despejados em rios (ALBUQUERQUE, 2010).

O tratamento de resíduos líquidos gerados na atividade de curtimento dá origem a resíduos semi-sólidos, lodos, que normalmente, são dispostos de forma inadequada em áreas agrícolas (AQUINO NETO; CAMARGO, 2000). Estes lodos são constituídos de materiais orgânicos de origem animal misturados com sais inorgânicos, e alguns desses componentes são nutrientes importantes para plantas e microrganismos. Entretanto, existem nesses lodos relativas quantidades de elementos químicos que podem ter efeitos negativos sobre a qualidade do solo e o crescimento das plantas (ARAUJO et al., 2011; SANTOS, 2010).

A disposição de resíduos no solo é uma prática cada vez mais utilizada. Para a aplicação de lodos de curtumes em áreas agrícolas, adotou-se a premissa de que, desde que atendidos critérios que garantam a minimização de riscos de poluição, tal prática deve proporcionar benefício agrícola para a cultura e/ou melhoria na utilização da área (CETESB, 1999).

Os substratos agrícolas para produção de mudas podem ser definidos como materiais adequados para providenciar a retenção das quantidades suficientes de água e de nutrientes, além de manter o pH compatível e de garantir adequada condutividade elétrica (TRIGUEIRO et al., 2003), com função de suportar o sistema radicular das mudas em crescimento (SILVA et al, 2011). Na composição do substrato, a fonte orgânica é responsável pela retenção da umidade e liberação dos nutrientes que serão absorvidos pelas plantas.

A utilização do lodo como substrato para mudas deve ser feito de forma criteriosa, afim de não aumentarem os riscos de contaminações dos solos e das matas ciliares ou aquíferos subterrâneos. Faz-se necessário que a aplicação do lodo em plantios florestais seja feita em concernência com a legislação vigente, por técnico habilitado, pois a presença de metais pesados e/ou organismos patogênicos no lodo acima dos teores permitidos impossibilita sua utilização em plantios florestais. Os danos ambientais causados pela aplicação indiscriminada do lodo podem ser sérios, causando bioacumulação, com reflexos na cadeia trófica (SIQUEIRA, 2010).

Estudos sobre a viabilidade da utilização do lodo na produção de mudas têm avançado conforme aumenta a demanda de substrato de qualidade e também aumenta a oferta de lodo tratado com necessidade de uma destinação final adequada (SIQUEIRA, 2010). A produção de mudas florestais também pode ser uma forma de utilização racional de lodo do caleiro, proveniente do processo primário de curtimento de couro. No entanto, a adição desse resíduo requer estabelecimento de dosagens limitadas que podem ser utilizadas, que poderá variar conforme as exigências nutricionais das espécies florestais e sua resistência aos teores dos elementos químicos fitotóxicos (FRANCZAK et al., 2008).

A partir da necessidade de se estudar o do uso do lodo de curtume na composição do substrato, este trabalho teve como objetivos avaliar o efeito da adição de lodo de curtume ao substrato comercial no crescimento de mudas de quatro espécies florestais nativas: aroeira salsa, mutambo, angico vermelho e angico branco e uma exótica, eucalipto, bem como avaliar a fitoextração de nutrientes e de cromo do substrato.

\section{MATERIAL E MÉTODOS}

O lodo de curtume utilizado no experimento foi obtido na linha de tratamento da ribeira do Curtume Vitapelli, localizado em Presidente Prudente, SP. No experimento foi utilizado um substrato comercial (Bioplant ${ }^{\circledR}$ ) recomendado para mudas florestais, cuja composição está apresentada na tabela 1 . O lodo foi secado a $65^{\circ} \mathrm{C}$ em estufa de aeração forçada durante cinco dias, em seguida realizou-se análise química do resíduo (Malavolta et al. 1997) que apresentou as seguintes concentrações químicas ( $\mathrm{g} \mathrm{kg}^{-1}$ ): 29,1 de N; 6,1 de P; 0,6 de K; 128,5 de Ca; 10,8 de Mg; 13,0 de S e 1,9 g de Cr. Após a secagem, o resíduo foi peneirado em granulometria de $2 \mathrm{~mm}$, para garantir homogeneidade e uniformidade de partículas, e em seguida foi misturado ao substrato, em diferentes dosagens, baseado na relação massa seca do lodo: massa do substrato a umidade aproximada de $40 \%$. Com este procedimento foram definidos os seguintes tratamentos: T0 $=0 \%$ de lodo na mistura; T5 $=5 \%$ de lodo na mistura; $\mathrm{T} 10=10 \%$ de lodo na mistura; $\mathrm{T} 15=15 \%$ de lodo na mistura; $\mathrm{T} 20=20 \%$ de lodo na mistura; T 25 = 25\% de lodo na mistura. A composição química do substrato após adi- 
ção do lodo (Tabela 1), utilizado no experimento, foi determinada de acordo com a metodologia descrita por Lanarv (1988), e para determinação de teor de cromo total nas amostras, seguiu-se o método de extração proposto por Malavolta et al. (1997), com determinação em espectrofotômetro de absorção atômica.

O delineamento experimental foi inteiramente casualizado, em esquema fatorial, $6 \times 5$, sendo avaliadas cinco doses de lodo de curtume e cinco espécies arbóreas florestais, com cinco repetições. Cada unidade do experimento foi constituída por cinco plantas resultando em 750 plantas.

Tabela 1. Caracterização química do substrato comercial após adição do lodo de curtume.

Table 1. Chemical analysis of the substrate after addition of tannery sludge.

\begin{tabular}{|c|c|c|c|c|c|c|c|c|c|c|c|}
\hline Tratamentos & $\mathbf{N}$ & $\mathbf{P}$ & $\mathbf{K}$ & $\mathbf{C a}$ & Mg & $\mathbf{S}$ & $\mathrm{Cr}$ & $\mathrm{Fe}$ & $\mathrm{Cu}$ & Mn & $\mathrm{Zn}$ \\
\hline & & & \multicolumn{4}{|c|}{------------ g kg$^{-1}$---------------- } & \multicolumn{5}{|c|}{----------'mg kg-1----------- } \\
\hline T0 & 6,0 & 1,3 & 0,4 & 13,8 & 6,7 & 1,5 & 70,6 & 8041 & 22,2 & 829 & 126 \\
\hline T5(5\% de lodo) & 7,3 & 1,3 & 0,6 & 17,9 & 7,5 & 1,5 & 294,9 & 8957 & 22,8 & 905 & 126 \\
\hline T10(10\% de lodo) & 7,5 & 1,3 & 0,6 & 20,2 & 7,6 & 1,6 & 302,8 & 9515 & 29,0 & 1064 & 120 \\
\hline T15(15\% de lodo) & 8,2 & 1,4 & 0,9 & 22,9 & 7,6 & 1,6 & 402,6 & 9800 & 34,7 & 1225 & 130 \\
\hline T20(20\% de lodo) & 8,4 & 1,6 & 1,1 & 23,1 & 8,2 & 1,8 & 524,2 & 10543 & 42,7 & 1325 & 132 \\
\hline T25(25\% de lodo) & 8,7 & 2,0 & 3,9 & 32,1 & 8,2 & 2,1 & 695,8 & 11005 & 61,7 & 1788 & 137 \\
\hline
\end{tabular}

Tubetes de $53 \mathrm{~cm}^{3}$ foram preenchidos com $30 \mathrm{~g}$ de substrato previamente preparado, conforme o tratamento. Nos substratos previamente umedecidos foram semeadas três sementes das seguintes espécies florestais: angico branco (Anadenanthera colubrina), angico vermelho (Anadenanthera macrocarpa), aroeira salsa (Schinus mole), mutambo (Guanzuma ulmifolia) e eucalipto (Eucalyptus urophylla). Após isto, os tubetes foram dispostos em suportes de aço, distanciados $5 \mathrm{~cm}$ um do outro e mantidos em ambiente protegido para crescimento de mudas, durante 120 dias. Após a germinação das sementes procedeu-se o desbaste das plântulas deixando apenas uma por tubete. Nessa fase a irrigação era periódica, efetuada por sistema de aspersão e sombreadas com tela sombrite (50\%).

Aos 120 dias após a semeadura (DAS), foram avaliados o diâmetro do colo com o auxilio de paquímetro $1 \mathrm{~cm}$ acima do nível do substrato. Em seguida, as plantas foram coletadas para avaliação das massas secas da parte aérea e do sistema radicular. O sistema radicular foi separado da parte aérea e lavado cuidadosamente, para não haver perda de raízes, em água corrente para retirada do substrato aderido. O sistema radicular e a parte aérea das plantas foram então acondicionadas em sacos de papel e levados à estufa de ventilação forçada regulada a $65^{\circ} \mathrm{C}$, até que a massa ficasse constante. Após, foi efetuada a pesagem em balança analítica, sendo em seguida coletadas amostras de folhas para realização de análises químicas de nutrientes e de teor de cromo no tecido vegetal, segundo a metodologia descrita por Malavolta et al. (1997).

Na ocasião da coleta das plantas também se retirou porções do substrato dos tubetes, de todos os tratamentos, com a finalidade de realização da análise de cromo total, através do método de Malavolta et al. (1997)

Os dados foram submetidos à análise de variância e ao teste de $\mathrm{F}$ ( $\mathrm{p}>0,05$ e 0,01) utilizando-se $\mathrm{o}$ aplicativo Sisvar. No caso do efeito significativo da interação procedeu-se a análise de regressão do fator quantitativo, doses de lodo de curtume. Os modelos matemáticos foram definidos com base na significância do teste $\mathrm{F}$ e no coeficiente de determinação $\left(\mathrm{R}^{2}\right)$.

\section{RESULTADOS E DISCUSSÃO}

A adição do lodo de curtume ao substrato conferiu ganhos crescentes na concentração de cálcio, cobre e manganês, mas não conferiu aumentos consideráveis de nitrogênio e fósforo, nutrientes importantes e de grandes demandas para crescimento de mudas (Tabela 1).

A produção de biomassa pelas mudas dos angicos branco e vermelho, tanto na parte aérea quanto no sistema radicular foram reduzidas com o aumento da proporção de lodo de curtume no substrato (Figuras 1 e 2 ). Por outro lado, as mudas de mutambo apresentaram aumentos em massa de raízes e de parte aérea, com os ajustes quadráticos mais significativos $(\mathrm{p}<0,01)$ enquanto que as de eucalipto e aroeira-salsa proporcionaram ajustes lineares crescentes em resposta ao aumento da proporção de lodo adicionado ao substrato. 
Silva et al. - Crescimento e fitoextração em espécies em

espécies florestais após adição de lodo de curtume no substrato

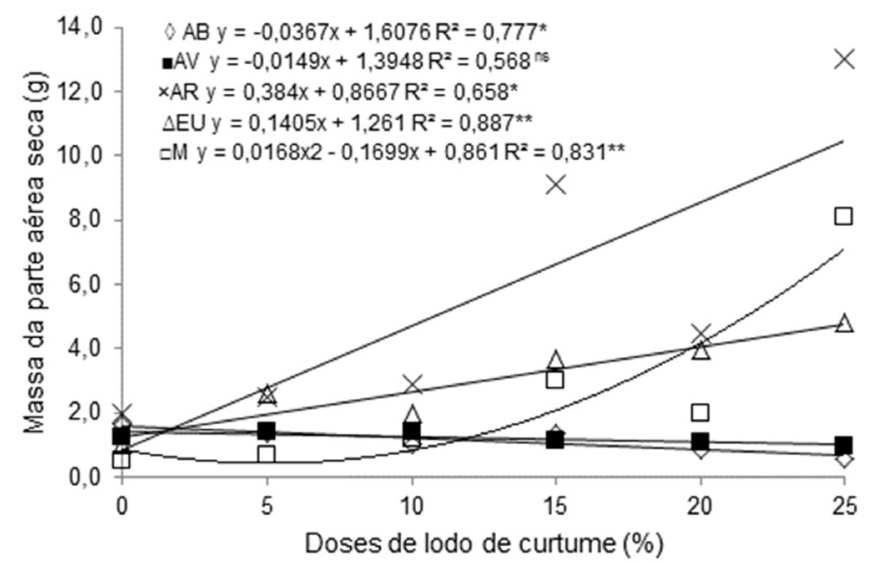

Figura 1. Massa seca na parte aérea de AB-Angico Branco, AV-Angico Vermelho, AR-Aroeira Salsa, EU-Eucalipto e M- Mutambo em função da adição de doses de lodo de curtume $(0,5,10,15,20$ e $25 \%)$ ao substrato. ** Coeficientes significativos $\mathrm{p}<0,01 ; *$ Coeficientes significativos $\mathrm{p}<0,05$.

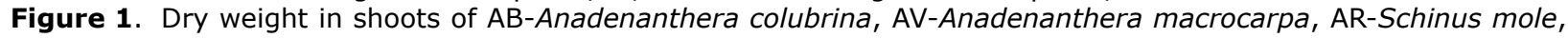
EU-Eucalyptus urophylla and M-Guanzuma ulmifolia, due to the addition of tannery sludge $(0,5,10,15$, 20 and $25 \%$ ) to the substrate. $* *$ Significant coefficients $p<0,01 ; *$ Significant coefficients $p<0,05$.

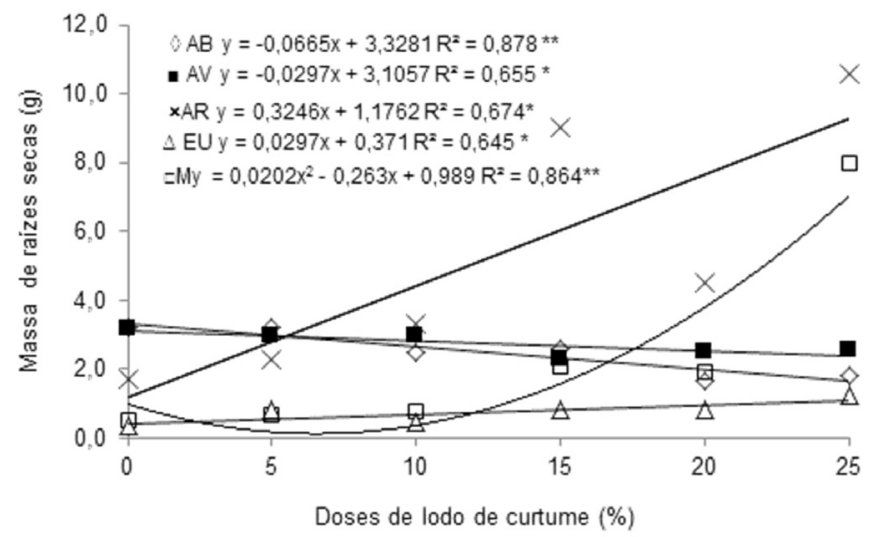

Figura 2. Massa seca do sistema radicular de AB-Angico Branco, AV-Angico Vermelho, AR- Aroeira Salsa, EU-Eucalipto e M- Mutambo, em função da adição de doses de lodo de curtume $(0,5,10,15,20$ e $25 \%)$ ao substrato. $* *$ Coeficientes significativos $p<0,01 ; *$ Coeficientes significativos $p<0,05$.

Figure 2. Dry weight in roots of AB-Anadenanthera colubrina, AV-Anadenanthera macrocarpa, AR-Schinus mole, EU-Eucalyptus urophylla and M-Guanzuma ulmifolia, due to the addition of tannery sludge $(0,5,10,15$, 20 and $25 \%)$ to the substrate. $* *$ Significant coefficients $p<0,01 ; *$ Significant coefficients $p<0,05$.

No tocante ao diâmetro do colo das plantas (Figura 3), apenas as mudas de eucalipto foram influenciadas, com o aumento do diâmetro, o qual se ajustou de forma significativa $(\mathrm{p}<0,05)$ ao aumento das doses de lodo no substrato. Nas demais espécies não foram obtidos efeitos do lodo na alteração do diâmetro do caule.

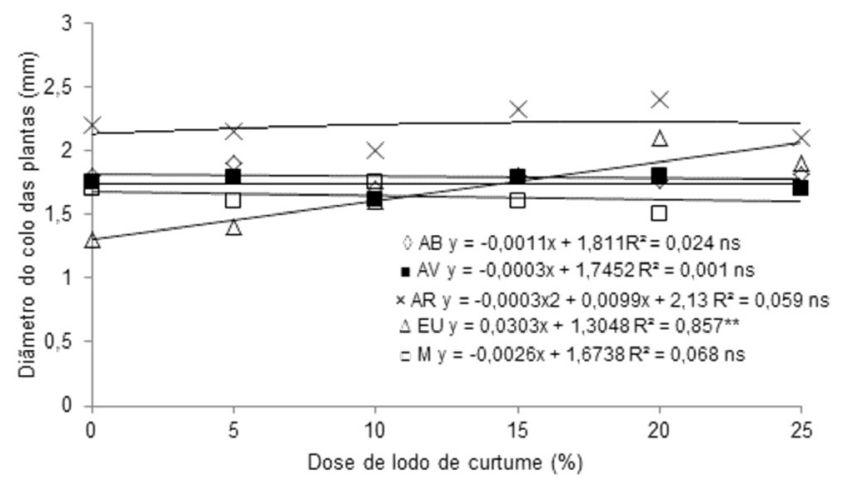

Figura 3. Diâmetro de colo das plantas de AB-Angico Branco, AV-Angico Vermelho, AR- Aroeira Salsa, EU-Eucalipto e M- Mutambo, em função da adição de doses de lodo de curtume (0, 5, 10, 15, 20 e 25\%) ao substrato. ** Coeficientes significativos $\mathrm{p}<0,01$; * Coeficientes significativos $\mathrm{p}<0,05$.

Figure 3. Root collar diameter of AB-Anadenanthera colubrina, AV-Anadenanthera macrocarpa, AR-Schinus mole, EU-Eucalyptus urophylla and M-Guanzuma ulmifolia, due to the addition of tannery sludge $(0,5,10,15$, 20 and $25 \%)$ to the substrate. ** Significant coefficients $p<0,01 ; *$ Significant coefficients $p<0,05$. 
As mudas de aroeira, mutambo e de eucalipto, responderam positivamente a incorporação crescente de lodo no substrato, na maioria dos parâmetros de crescimento avaliados. Em estudo semelhante, a adição de apenas 3\% de lodo de curtume ao substrato comercial proporcionou o melhor desempenho para a produção de mudas de Jacaranda cuspidifolia (FRANCZAK, 2008). Em outro estudo semelhante, a utilização de doses crescentes de lodo de curtume no cultivo de eucalipto, em ambiente de estufa, resultou na melhoria de parâmetros biométricos da planta e físico-químico do solo (GAMBA, 2012). Estes resultados podem auxiliar na definição de doses de lodo que possam ser utilizadas nas diferentes espécies florestais, enfatizando-se que algumas espécies podem não apresentar respostas ou respostas negativas a adição do resíduo.

Miao e Yan (2013) citaram que o crescimento de mudas de três espécies de plantas ornamentais (Mirabilis jalapa, Impatiens balsamin e Tagetes erecta) em vasos com solo, contendo lodo de curtume foi considerado satisfatório, com as espécies Mirabilis jalapa e Impatiens balsamin aumentando seu crescimento em sintonia com o aumento das doses de lodo até a concentração de 5\% de lodo adicionado ao solo. Esses autores afirmam também que os solos tratados com diferentes concentrações de lodo, contendo cromo, podem promover o crescimento das plantas que servirão de fitoacumuladoras de cromo. GUPTA; SINHA (2007) verificaram que Chenopodium album apresentou maior taxa fotossintética e maior teor de proteína foliar quando cresceu em solo acrescido com doses de lodo de curtume.

Ocorreram poucos ajustes significativos para acúmulo de macronutrientes nas diferentes espécies avaliadas, destacando-se apenas o acúmulo de fósforo e potássio em algumas espécies. O acúmulo de fósforo (P) no tecido foliar das cinco espécies (Figura 4) aumentou nas espécies de aroeira e mutambo, com ajuste linear. Entretanto, verificou-se redução no acúmulo de fósforo mesmo com aumentos a dose de lodo no substrato, nos angicos. Isto pode ser explicado, em parte, pelo maior crescimento das plantas nestes tratamentos e em consequência da maior absorção de P provocando o chamado "efeito de diluição" do elemento químico na planta (MALAVOLTA, et al., 1997). O lodo de curtume tem sido apresentado como um resíduo pobre em fósforo e geralmente conduz a deficiências nos teores foliares desse elemento na planta, em estudos de avaliação nutricional após a disposição desse resíduo no solo (GAMBA, 2012). Com relação ao potássio pode ser destacado o maior acúmulo, com ajuste linear, para o mutambo (Figura 5)

Com relação ao acúmulo de micronutrientes, também não ocorreram ajustes significativos, na maioria dos elementos. Houve o maior acúmulo de manganês $(\mathrm{Mn})$ pelas espécies de mutambo e eucalipto avaliados em resposta ao aumento das doses de lodo (Figura 6). Pode ser destacado, o ajuste linear $(\mathrm{p}<0,01)$ proporcionado pela absorção de Mn pelas mudas de eucalipto em resposta as doses de lodo aplicadas. Resultado semelhante foi encontrado por Shukla et al. (2011), que também encontrou a maior absorção deste elemento pelo eucalipto em áreas com aplicação de lodo de curtume. Sobre este fato, Malavolta et al. (1997) mencionaram que o manganês é imprescindível para a fotossíntese das plantas C3,caso do eucalipto. Em estudo de cultivo de espinafre, com aplicação de doses de lodo de curtume em solo, acondicionado em vasos, SINHA et al. (2007), que os micronutrientes são mais assimilados pelas folhas do que pelas raízes e que zinco e manganês foram os elementos mais assimilados na dose de $25 \%$ de lodo no solo.

A aroeira-salsa, e o mutambo apresentaram-se como de maior capacidade de absorção e acúmulo de cromo no tecido foliar, dentre as espécies avaliadas, ajustando-se de forma linear e quadrática $(\mathrm{p}<0,01)$, respectivamente, às doses de lodos aplicadas no substrato (Figura 7$)$. A capacidade de acúmulo do metal averiguado no tecido foliar da aroeira-salsa, pode também fundamentar a melhor resposta de crescimento dessa espécie, quando se aumentou as doses de lodo no substrato (Figuras 1 e 2). De acordo com Cipriani et al (2012) a absorção de cromo pelas plantas inicia pelo acúmulo do metal nos vacúolos radiculares, como forma de defesa das plantas, e aos poucos ocorre a translocação para a parte aérea acumulando-se na parede do xilema. Shukla et al. (2011) verificaram que a capacidade de acumulação de metais em espécies florestais aumentam com sua maturidade, verificando-se aumento de até seis vezes no período de três meses a um ano de idade. Apesar desse estudo ter avaliado o acúmulo de cromo na parte aérea (Figura 7), López-Luna (2009) apresentaram que a acumulação de cromo em plantas é mais consistente na raiz do que na parte aérea. Em estudo com aplicação de lodo de curtume no solo foi relatado também que é notória a translocação de nutrientes da raiz para a folha, como fósforo, potássio, enxofre, boro, cobre, zinco, cálcio, ferro, manganês, cromo e sódio (CARY et al., 1977). 
Silva et al. - Crescimento e fitoextração em espécies em

espécies florestais após adição de lodo de curtume no substrato

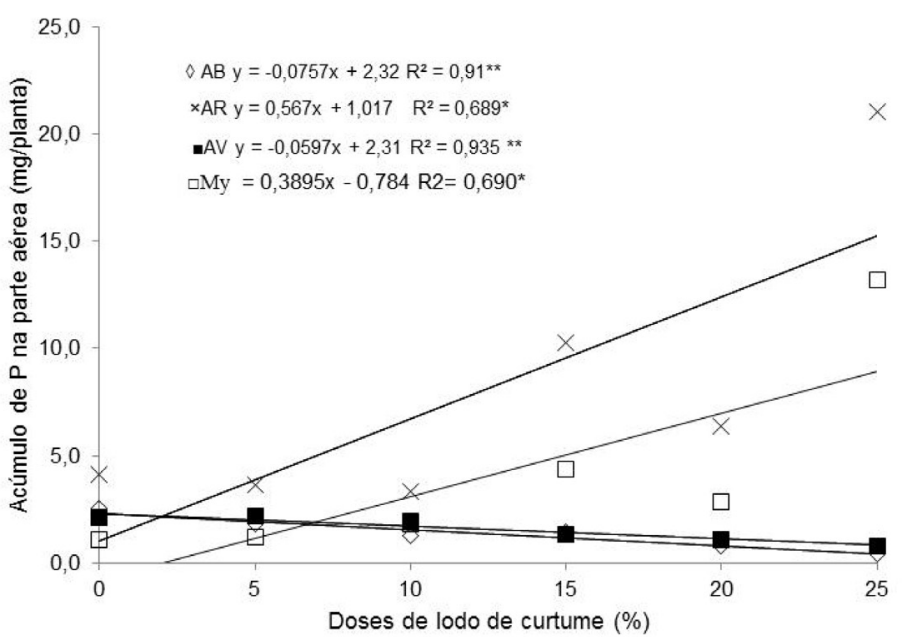

Figura 4. Acúmulo de fósforo em AB-Angico Branco, AV-Angico Vermelho, AR- Aroeira Salsa, EU-Eucalipto e M- Mutambo, em função da adição de lodo de curtume $(0,5,10,15,20$ e 25\%) ao substrato. ** Coeficientes significativos $\mathrm{p}<0,01 ; *$ Coeficientes significativos $\mathrm{p}<0,05$.

Figure 4. Phosphorus accumule in AB-Anadenanthera colubrina, AV-Anadenanthera macrocarpa, AR-Schinus mole, EU-Eucalyptus urophylla and M-Guanzuma ulmifolia, due to the addition of tannery sludge $(0,5,10,15$, 20 and $25 \%)$ to the substrate. $* *$ Significant coefficients $\mathrm{p}<0,01 ; *$ Significant coefficients $\mathrm{p}<0,05$.

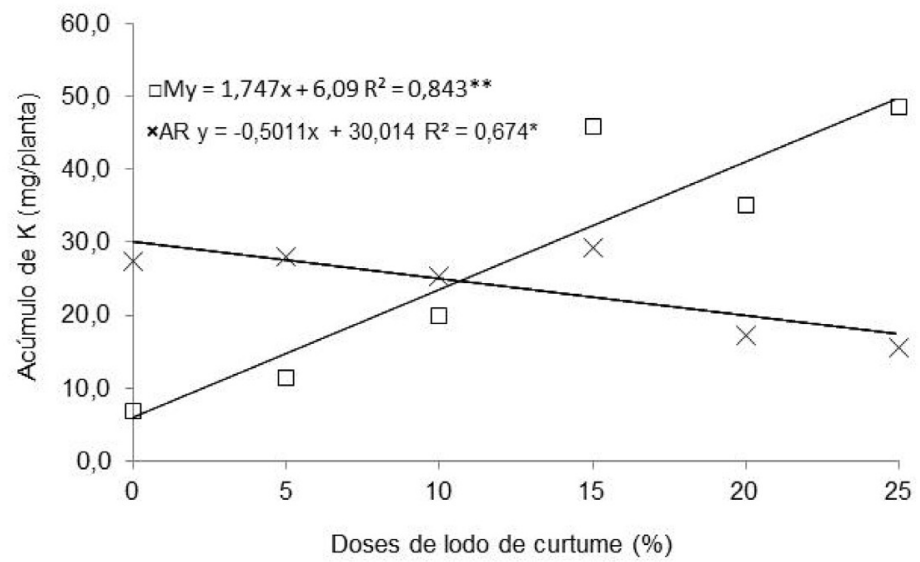

Figura 5. Acúmulo de potássio em AB-Angico Branco , AV-Angico Vermelho, AR- Aroeira Salsa, EU-Eucalipto e MMutambo, em função da adição de lodo de curtume (0, 5, 10, 15, 20 e 25\%) ao substrato. ** Coeficientes significativos $\mathrm{p}<0,01$; Coeficientes significativos $\mathrm{p}<0,05$.

Figure 5. Potassium accumule in AB-Anadenanthera colubrina, AV-Anadenanthera macrocarpa, AR-Schinus mole, EU-Eucalyptus urophylla and M-Guanzuma ulmifolia, due to the addition of tannery sludge $(0,5,10,15$, 20 and $25 \%$ ) to the substrate. $* *$ Significant coefficients $p<0,01 ; *$ Significant coefficients $p<0,05$.

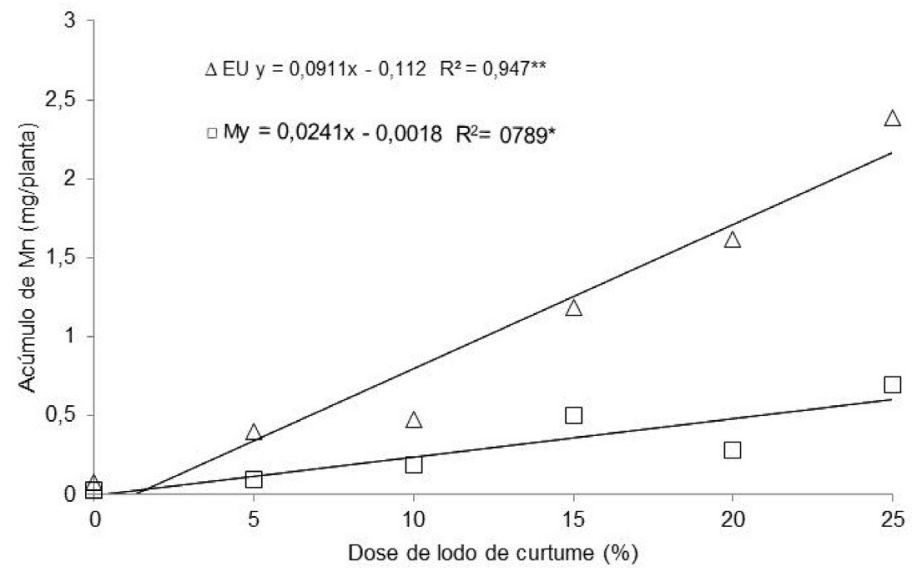

Figura 6. Acúmulo de manganês em AB-Angico Branco, AV-Angico Vermelho, AR- Aroeira Salsa, EU-Eucalipto e MMutambo, em função da adição de lodo de curtume $(0,5,10,15,20$ e $25 \%)$ ao substrato. ** Coeficientes significativos $\mathrm{p}<0,01 ; *$ Coeficientes significativos $\mathrm{p}<0,05$.

Figure 6. Manganese accumule in AB-Anadenanthera colubrina, AV-Anadenanthera macrocarpa, AR-Schinus mole, EU-Eucalyptus urophylla and M-Guanzuma ulmifolia, due to the addition of tannery sludge $(0,5,10,15$, 20 and $25 \%)$ to the substrate. $* *$ Significant coefficients $p<0,01 ; *$ Significant coefficients $p<0,05$. 


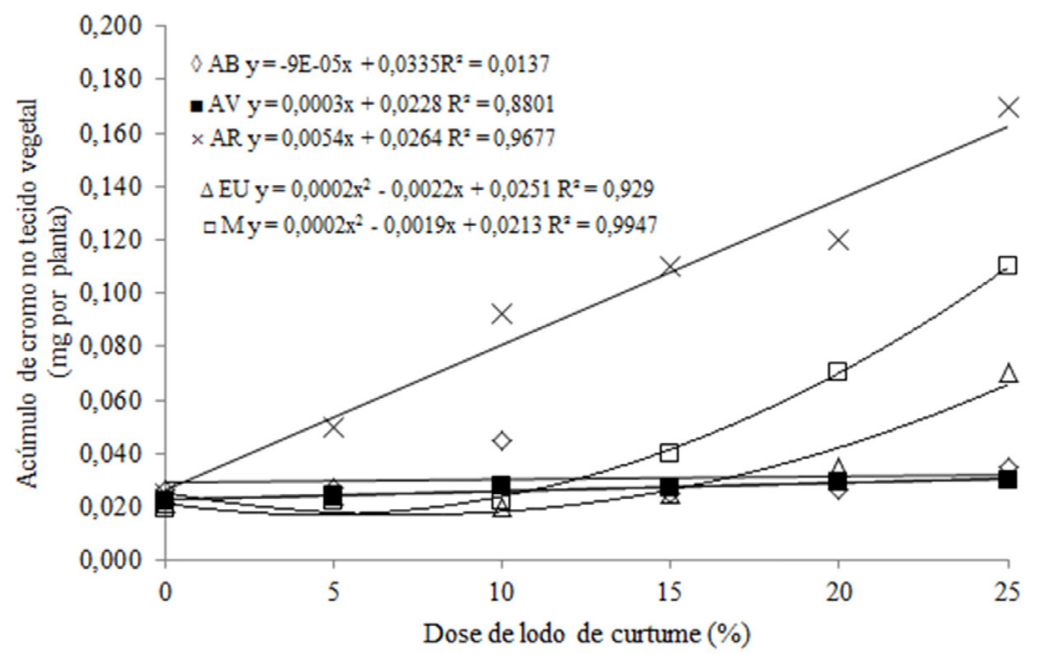

Figura 7. Acúmulo de cromo na parte aérea de AB-Angico Branco, AV-Angico Vermelho, AR- Aroeira Salsa, EU-Eucalipto e M- Mutambo, em função da adição de lodo de curtume (0, 5, 10, 15, 20 e 25\%) ao substrato. ** Coeficientes significativos $\mathrm{p}<0,01$; Coeficientes significativos $\mathrm{p}<0,05$.

Figure 7. Chromium accumule in shoots AB-Anadenanthera colubrina, AV-Anadenanthera macrocarpa, AR-Schinus mole, EU-Eucalyptus urophylla and M-Guanzuma ulmifolia, due to the addition of tannery sludge $(0,5,10$, 15,20 and $25 \%$ ) to the substrate. $* *$ Significant coefficients $p<0,01$; $*$ Significant coefficients $p<0,05$.

Ocorreram maiores decréscimos na concentração de cromo, no substrato, após o crescimento do eucalipto e pouca redução deste metal quando se produziu o angico vermelho, com ajustes significativos a 1\% (Figura 8). Shukla et al. (2011) em estudo de fitoremediação com espécies florestais, apresentaram reduções de 70,2 \% de cromo do solo após um ano de cultivo, com destaque para a maior acumulação do metal em Prosopis juliflora. Myao e Yan (2013) em estudo semelhante com plantas ornamentais, encontraram remoções de cromo em torno de $20 \%$ após 120 dias de crescimento. Os resultados encontrados nesse experimento, quando se produziu eucalipto mostram que houve reduções de cerca de $80 \%$ no cromo do substrato, no tratamento com a maior dose do resíduo, após 90 dias de crescimento das mudas (Tabela 1 e Figura 8). Apesar de que os resultados de acúmulo de cromo na parte aérea de eucalipto não se destacaram das outras espécies o que pode estar relacionado ao maior acúmulo do metal na raiz (não avaliado nesse estudo). Mughini et al (2013) relataram que o eucalipto acumula uma quantidade considerável de cromo nos tecidos, mas enfatizam que a compartimentalização do metal pode ser influenciada pelas condições ambientais no seu cultivo.

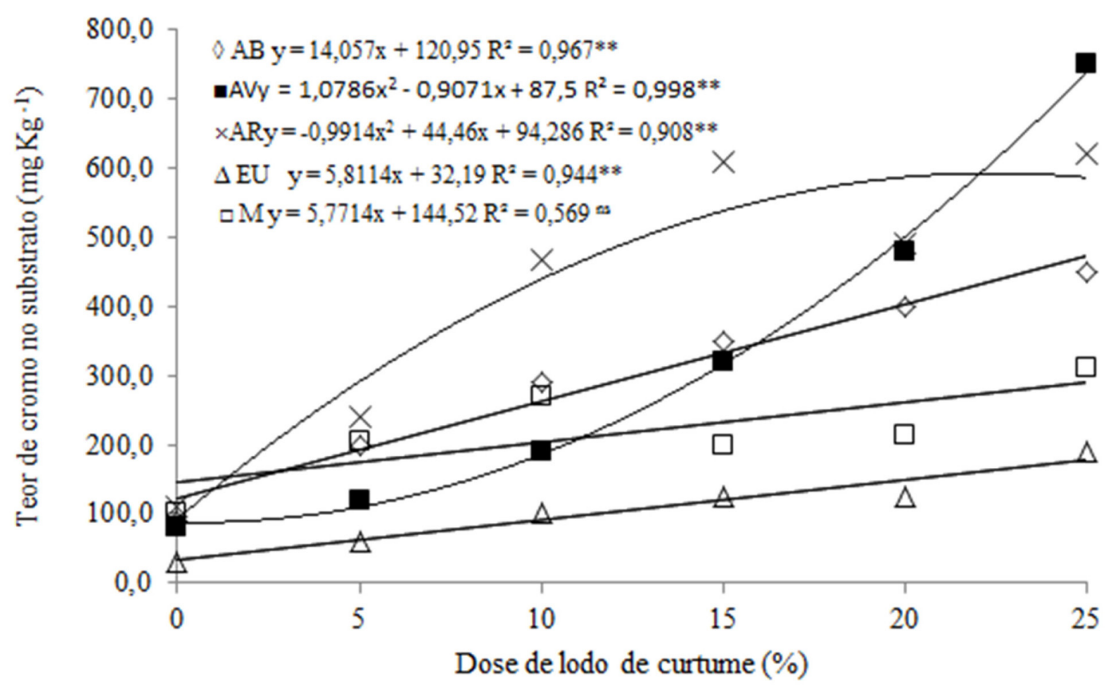

Figura 8. Teor de cromo após a adição de lodo de curtume (0, 5, 10, 15, 20 e 25\%) ao substrato após o crescimento de AB-Angico Branco , AV-Angico Vermelho, AR- Aroeira Salsa, EU-Eucalipto e M- Mutambo. ** Coeficientes significativos $p<0,01 ; *$ Coeficientes significativos $p<0,05$.

Figure 8. Chromium contents in AB-Anadenanthera colubrina, AV-Anadenanthera macrocarpa, AR-Schinus mole, EU-Eucalyptus urophylla and M-Guanzuma ulmifolia, due to the addition of tannery sludge $(0,5,10,15$, 20 and $25 \%$ ) to the substrate. $* *$ Significant coefficients $p<0,01 ; *$ Significant coefficients $p<0,05$. 
Espécies florestais podem ser usadas na fitorremediação de solos contaminados com potencial para extrair metais pesados do solo. Shukla et al. (2011) avaliaram o potencial fitorremediador de espécies lenhosas em solos contaminados com resíduo de curtume e constataram que o Eucalyptus tereticornis apresentou grande capacidade de acumulação de $\mathrm{Fe}, \mathrm{Cu}, \mathrm{Mn}$ e $\mathrm{Zn}$, enquanto que as espécies Terminalia arjuna, Prosopis juliflora e Dendrocalamus strictus se mostraram eficientes em acumulação de $\mathrm{Cd}$, Cr, Ni e Pb. Por este motivo, os autores indicam estas espécies para minimizar o impacto ambiental de resíduos industriais. Resultado semelhante foi encontrado por Sakthivel e Vivekanandan (2009) em estudo utilizando três espécies florestais (Melia azedarach, Azadirachta indica e Leucaena leucocephala) também para fitorremediação em solos com resíduos de curtume.

O uso de lodo de curtume na agricultura tem sido discutido em diferentes estudos disponíveis na literatura (ARAUJO et al., 2011; MARTINES et al., 2005; AQUINO NETO; CAMARGO, 2000). Com frequência nesses estudos são avaliados: a dinâmica do cromo, os riscos de salinização e consequente aumento da condutividade elétrica no solo. Tavares et al. (2013) concluíram que o lodo de curtume tem potencial de correção da acidez do solo, com aumento pouco expressivo dos indicadores de salinidade, sodicidade e do teor de $\mathrm{Cr}^{+3}$ disponível. No tocante ao cromo também existe a falta de comprovação científica da oxidação do $\mathrm{Cr}^{+3} \mathrm{em} \mathrm{Cr}^{+6}$ após adição do resíduo no solo (AQUINO NETO; CAMARGO, 2000; KONRAD; CASTILHOS, 2002). Por outro lado, a maioria dos trabalhos citados anteriormente indica sempre algum benefício da aplicação do lodo nos sistemas agrícolas, podendo ser destacado: correção e fertilização do solo e aumento da atividade microbiana.

A proposta desse estudo de incorporar o lodo de curtume no substrato pode reduzir impactos ambientais, pela possibilidade de melhor distribuição do resíduo no solo, menores taxas de aplicação, além da possibilidade da fitoextração de elementos com potencial de poluição ao ambiente. Considerando-se a dose máxima avaliada de $25 \%$ do resíduo misturado ao substrato e o número aproximado de plantas por hectare em reflorestamentos, no caso do eucalipto, 1670 plantas por hectare, a taxa de aplicação ficará próxima de 12,5 kg de lodo de curtume seco por hectare. Ou no caso do lodo avaliado no estudo, 22 gramas de cromo por hectare. Em 2012, a área plantada com eucalipto no país atingiu 5,0 milhões de hectares, representando 71,0\% do total das florestas plantadas (ABRAF, 2013). Neste contexto, esta área poderia atender a disposição de até 62.500 toneladas de lodo seco. Segundo a Cetesb (2014), pode ser estimado uma produção anual de 168.000 toneladas de lodo de curtume, na base seca, no Brasil. Ou seja, a adição de $25 \%$ do resíduo no substrato para produção de mudas de eucalipto pode atender a disposição, com redução de impactos, de um terço do lodo de curtume gerado pelo curtumes brasileiros.

Pode ser destacado que a maioria das espécies florestais avaliadas neste estudo, exceto os angicos, apresentaram ganhos de crescimento com o acréscimo do lodo de curtume ao substrato e que não foram detectados sintomas de fitotoxidez em razão do uso do resíduo nas doses empregadas nesse estudo. São de fundamental importância novos estudos com avaliação de crescimento das plantas em condições de campo.

\section{CONCLUSÕES}

- As espécies de aroeira salsa, eucalipto e mutambo responderam positivamente à adição de até 25\% de lodo de curtume no substrato para produção de mudas.

- A aroeira salsa apresentou a maior capacidade de absorção de cromo na parte aérea e também se destacou como de melhor crescimento em resposta a adição do lodo no substrato.

- O teor de cromo no substrato foi reduzido após o crescimento de todas as espécies florestais avaliadas, com destaque para o desempenho do eucalipto.

\section{REFERÊNCIAS BIBLIOGRÁFICAS}

ABRAF - ASSOCIAÇÃO BRASILEIRA DE PRODUTORES DE FLORESTAS PLANTADAS. Anuário estatístico da ABRAF: ano base 2012. Brasília, 2013. 130 p.

ALBUQUERQUE, C. Sustentabilidade agrícola, 2010. Disponível em: <http://www.esalq.usp.br/noticia/ detalhe.php?id=945\&ano=2010>. Acesso em: 03 dez. 2010. 
AQUINO, V. N.; CAMARGO, O. A. Crescimento e acúmulo de cromo em alface cultivada em dois latossolos tratados com crcl3 e resíduos de curtume. Revista Brasileira de Ciência do Solo, Viçosa, v. 24, n. 2, p. 225$235,2000$.

ARAÚJO, F. F. Disponibilização de fósforo, correção do solo, teores foliares e rendimento de milho após a incorporação de fosfatos e lodo de curtume natural e compostado. Acta Scientiarum Agronomy, Maringá, v. 33, n. 2, p. 355-360, 2011.

CARY, E. E.; ALLAWAY, W. H.; OLSON, O. E. Control of chromium concentration in food plants. 1. Absorption and translocation of chromium by plants. Journal of Agricultural and Food Chemistry, v. 25, n. 2, p. 300$304,1977$.

CETESB - COMPANHIA DE TECNOLOGIA DE SANEAMENTO AMBIENTAL. Aplicação de lodos de curtume em áreas agrícolas - Critérios para projeto e operação. São Paulo, 1999. 32 p.

CETESB - COMPANHIA DE TECNOLOGIA DE SANEAMENTO AMBIENTAL. Guia Técnico Ambiental de Curtumes (Série P + L). São Paulo, 2014, 89 p.

CIPRIANI, H. N.; BASTOS, A. R. R.; CARVALHO, J. G.; COSTA, A. L.; OLIVEIRA, N. P. Chromium toxicity in hybrid eucalyptus (Eucalyptus urophylla) cuttings, Journal of Plant Nutrition, v. 35, n. 11, p. 1618-1638, 2012.

FRANCZAK, D. D.; MARQUES, R.; RONDON NETO, R. M.; LIMA, V. S. Adição de dosagens de lodo de curtume em substrato comercial para produçao de mudas de caroba (Jacaranda cuspidifolia Mart.). In: ENCONTRO NACIONAL SOBRE SUBSTRATOS PARA PLANTAS, 2008, Fortaleza. Anais... Fortaleza: EMBRAPA Agroindústria Tropical, 2008.

GAMBA, V. S. Avaliação do lodo de curtume como fonte de nutrientes para o crescimento inicial de eucalipto. Dissertação (Mestrado) - Faculdade de Ciências Agrárias, Universidade Estadual Paulista “Julio de Mesquita Filho", Botucatu, 2012.

GUPTA, A. K.; SINHA, S. Phytoextraction capacity of the plants growing on tannery sludge dumping sites, Bioresource Technology, Essex, v. 98, n. 09, p. 1788 1794, 2007.

IPEA - INSTITUTO DE PESQUISA ECONÔMICA APLICADA. Diagnóstico dos resíduos sólidos urbanos: Relatório de Pesquisa. Brasília: Ipea, 2012.

KONRAD, E. E.; CASTILHOS, D. D. Alterações químicas do solo e crescimento do milho decorrente da adição do lodo de curtume. Revista Brasileira de Ciência do Solo, Viçosa, v. 26, n. 1, p. 257-265, 2002.

LANARV - LABORATÓRIO DE REFERÊNCIA VEGETAL. Análise de corretivos, fertilizantes e inoculantes. Métodos oficiais. Brasília: Ministério da Agricultura, Secretaria de Defesa Agropecuária, 1988. 104 p.

LÓPEZ-LUNA, J.; GONZÁLEZ-CHÁVEZ, M.C.; ESPARZA-GARCÍA F.J.; RODRÍGUEZ-VÁZQUEZ, R. Toxicity assessment of soil amended with tannery sludge, trivalent chromium and hexavalent chromium, using wheat, oat and sorghum plants. Journal of Hazardous Materials, v.163, n. 2-3, p. 829-834, 2009.

MALAVOLTA, E.; VITTI, G. C.; OLIVEIRA, S. A. Avaliação do estado nutricional das plantas. Piracicaba: POTAFOS, 1997. 201 p.

MARTINES, A. M. Impacto do lodo de curtume nos atributos biológicos e químicos do solo. 2005.74 p. Dissertação (Mestrado em Agronomia/Solos e Nutrição de Plantas) - Escola Superior de Agricultura "Luiz de Queiroz", Universidade de São Paulo, Piracicaba, 2005. 
Silva et al. - Crescimento e fitoextração em espécies em

espécies florestais após adição de lodo de curtume no substrato

MIAO, Q; YAN, J. Comparison of three ornamental plants for phytoextraction potential of chromium removal from tannery sludge. Journal de Mater Cycles Waste Management, v. 15, p. 98-105, 2013.

MUGHINI, G.; ALIANIELLO, F.; BENEDETTI, A.; GRAS, L. M.; GRAS, M. A.; SALVATI, L. Clonal variation in growth, arsenic and heavy metal uptakes of hybrid Eucalyptus clones in a Mediterranean environment. Agroforest System, Dordrecht, v. 87, n. 4, p. 755-766, 2013.

SAKTHIVEL, V.; VIVEKANANDAN, M. Reclamation of tannery polluted soil through phytoremediation. Physiology and Molecular Biology of Plants, v. 15, n. 2, p. 175-180, 2009.

SANTOS, J. A. Compostagem do lodo de curtume e seu uso agrícola: Efeito sobre indicadores biológicos de qualidade do solo. 2010, 99 p. Dissertação (Mestrado em Agronomia) - Universidade Federal do Piauí, Teresina, 2010.

SHUKLA, O. P.; JUWARKAR, A. A.; SINGH, S. K.; KHAN, S.; RAI, U. N. Growth responses and metal accumulation capabilities of woody plants during the phytoremediation of tannery sludge. Waste Management, v. 31, n. 1, p. 115-123, 2011.

SILVA, J. D. C.; LEALI, T. T. B.; ARAÚJO, R. M.; GOMES, R. L. F.; ARAÚJO, A. S. F.; MELO, W. J. Emergência e crescimento inicial de plântulas de salsa ornamental e celosia em substrato à base de composto de lodo de curtume. Ciência Rural. Santa Maria, v. 41 n. 3, p. 412-417, 2011.

SINHA, S.; MALLICK, S.; MISRA, R. K.; SINGH, S.; BASANT A.; GUPTA A. K. Uptake and translocation of metals in Spinacia oleracea L. grown on tannery sludge-amended and contaminated soils: Effect on lipid peroxidation, morpho-anatomical changes and antioxidants. Chemosphere, Oxford, v. 67, n. 1, p. 176-187, 2007.

SIQUEIRA, C. S. S. Utilização de resíduos agroindustriais em plantios florestais, 2010. Disponível em: <http://www.if.ufrri.br/inst/monografia/2010I/CarolinaSouza.pdf>. Acesso em: 20 ago. 2012.

TAVARES, L. S. Lodo do curtimento e sua influência na produção de mudas de paricá e nas propriedades químicas do solo. Ciência Florestal, Santa Maria, v. 23, n. 3, p. 357-368, 2013.

TRIGUEIRO, R. M.; GUERRINI, I. A. Uso de biossólidos como substrato para produção de mudas de eucalipto. Scientia Forestalis, Piracicaba, n. 64, p. 150-162, dez. 2003.

Recebido em 05/05/2015

Aceito para publicação em 21/06/2016 